\title{
Amount and distribution of selected biologically active factors in amniotic membrane depends on the part of amnion and mode of childbirth. Can we predict properties of amnion dressing? A proof-of-concept study
}

\author{
MAEGORZATA LITWINIUK ${ }^{1}$, MAEGORZATA RADOWICKA², ALICJA KREJNER ${ }^{\prime}$, \\ ANNA ŚLADOWSKA ${ }^{l}$, TOMASZ GRZELA ${ }^{l}$ \\ 'Histology and Embryology Department, Center for Biostructure Research, Medical University of Warsaw, Poland \\ ${ }^{2} 1^{\text {st }}$ Department of Gynecology and Obstetrics, Center for Biostructure Research, Medical University of Warsaw, Poland
}

\begin{abstract}
Aim of the study: The amniotic membrane is used as a dressing material, e.g. in ocular surgery or treatment of non-healing wounds. Of note, results of previous studies differ significantly, presumably due to the biological properties of amnion. Some authors suggest that these properties may depend on inter-donor variations, as well as the method of delivery. The aim of our study was to analyse the content of selected factors important for tissue regeneration in various areas of amnion samples originating from elective caesarean sections and on-term natural deliveries.

Material and methods: Cervical and placental samples of amniotic membranes originating from physiological deliveries and caesarean sections have been collected with subsequent preparation of amniotic membrane extracts. The screening of amnion samples was performed using a proteome microarray system.

Results: In all of the amnion samples high amounts of angiogenin, IGF-binding proteins-1, -2, and -3, serine protease inhibitor E1, and TIMP-1 were detected. Important variations in the content of these factors were observed between physiological delivery and caesarean section-derived membranes, as well as between placental and cervical portions of the same membrane.

Conclusions: Our study has shown that the content of selected growth factors and regulators of ECM turnover in amniotic membrane samples vary between various donations, and that they depend on the region of the membrane or delivery method. This may determine its potential applications in wound treatment and ophthalmologic surgery. However, our observations require further verification in clinical settings.
\end{abstract}

Key words: angiogenesis, amniotic membrane, chronic inflammation.

(Centr Eur J Immunol 2018; 43 (1): 97-102)

\section{Introduction}

The amniotic membrane (AM), the innermost layer of foetal membranes, which protects the embryo during pregnancy, is a valuable biological material with a wide range of applications in clinical medicine. In tissue engineering AM serves as a scaffold supporting cell growth and migration [1, 2]. It has been used as a graft for ocular surface reconstruction, pleural and pericardial closure, and as a conduit for peripheral nerve regeneration [3-7]. Several studies have shown the clinical usefulness of amnion in wound management, especially in treatment of severe burns and chronic ulcers [8]. However, results of these studies, especially in regard to treatment effectiveness, differ significantly between reports and between treated individuals $[9,10]$. Several studies have shown that fresh, as well as sterilised amnion specimens, contain a wide range of various cytokines, including growth and differentiation factors $[11,12]$. It is plausible that the observed alternate influence of amniotic membrane may be due to the variable content of the mentioned factors between amnion samples originating from different donors. Indeed, in our

Correspondence: Małgorzata Litwiniuk, MD, Histology and Embryology Department, Center for Biostructure Research, Medical University of Warsaw, 5 Chałubinskiego St., 02-004 Warsaw, Poland, e-mail: malgosia.litwiniuk@gmail.com Submitted: 11.12.2016; Accepted: 03.01.2017 
previous pilot study we assessed amniotic membrane samples originating from different donors using the proteomic microarray system [13]. The results of this study revealed certain differences in the profile of biologically active factors among samples obtained from different donations. Moreover, some authors reported variations concerning the AM morphology and histological structure depending on the specific region of each AM. Usually, three different areas of the amnion: cervical (apical), placental, and a midzone, are distinguished [14]. The cervical area is a region of the membrane overlying the cervix, where the amnion ruptures prior to delivery. Significantly thinner and weaker than the rest of the membrane, with less epithelial cells, it is often described as a "zone of extreme morphology" [15-18]. In addition, some variations in the content of several biologically active factors involved in tissue regeneration, including epidermal growth factor (EGF), transforming growth factor $\beta$ (TGF- $\beta$ ), and matrix metalloproteinase (MMP)-9, between cervical and placental area of the AM, have been reported [19-21]. Furthermore, recent studies suggest that the biological properties of the amniotic membrane may also depend on the duration of gestation, as well as the mode of childbirth [22, 23].

Therefore, the aim of the present proof-of-concept, screening study was to assess and compare the content of selected biologically active factors involved in tissue regeneration in the amnion samples originating from the cervical and placental area. To clarify whether the content of these factors may depend on the method of delivery, samples obtained from elective caesarean sections, as well as on-term natural (physiological) deliveries, were assessed.

\section{Material and methods}

\section{Amniotic membrane samples - collection and preparation}

Amnion samples were collected in the Obstetrics and Gynaecology Department of Warsaw Medical University Hospital. A total of seven membranes were collected: four AM samples originating from spontaneous deliveries at term, and three AM samples originating from elective caesarean sections. Written, informed consent was obtained from all donors of amnion samples. The concept of the study was reviewed and approved by the Local Bioethics Committee. The study procedures conformed to the ethical guidelines of the World Medical Association Declaration of Helsinki.

From each amniotic membrane sample a cervical and placental portion was separated, according to the method described by Moore et al. [21]. Shortly, the placenta and its membranes, collected after the delivery, were placed on a cutting board and cut perpendicularly to the placenta surface, up to the placental rim. Once the foetal membranes lay flat, samples were taken from the area overlying the placenta surface and from the region most distant from pla- centa, identified as a cervical area of the membrane. Then, the amnion membranes were separated from the decidua layer and cut into fragments of approximately $1 \mathrm{~cm}^{2}$, which were then used to prepare amniotic membrane extracts.

Subsequently, amniotic membrane samples were immersed in $1 \%$ Triton X-100 in phosphate-buffered saline, supplemented with cOmplete Mini, a mixture of broadrange protease inhibitors (Roche Diagnostics, Mannheim, Germany), and mechanically dispersed using glass homogeniser. The obtained suspensions were centrifuged, and supernatants were collected in fresh tubes, aliquoted, and stored until being used for further analysis.

\section{Protein microarray}

The assay was performed using the Proteome Profiler kit (R\&D Systems Inc., Minneapolis, USA), as described in the manufacturer's protocol. $200 \mu \mathrm{l}$ of standardised amniotic membrane extracts were mixed with a cocktail of biotinylated detection antibodies and applied onto nitrocellulose membranes spotted with respective capture antibodies. After overnight incubation at $8^{\circ} \mathrm{C}$, the membranes were washed and then incubated with streptavidin-horseradish peroxidase conjugate, followed by use of a chemiluminescence detection system. Finally, the membranes were exposed to the X-ray film (Agfa-Geavert, Mortsel, Belgium) for 5-15 min to achieve optimal intensity of the signal. After development the film was scanned, and the optical density of each analysed spot was assessed using GelWorks 2D software (UVP, Cambridge, UK). Then, the optical density of respective factors on each membrane was compared to the optical density of positive control spots, and their relative amount in amnion samples was expressed as a sample-to-control ratio.

\section{Results}

In all of the amnion samples high amounts of angiogenin (ANG), insulin-like growth factor-binding proteins (IGFBP)-1, -2, and -3, as well as serine protease inhibitor (Serpin) E1 and tissue inhibitor of metalloproteinase-1 (TIMP-1), were detected. The mean and median concentrations of these factors in amniotic membrane samples derived from caesarean sections and physiological deliveries are presented in Table 1.

All amniotic membranes derived from elective caesarean sections were characterised by lower mean amounts of ANG, IGFBP-2, IGFBP-3, and TIMP-1 than membranes obtained after physiological deliveries. The mean levels of IGFBP-1 and Serpin E1 were similar in both membrane groups.

The intra-donor variations in distribution of selected biologically active factors between cervical and placental regions of each membrane were also observed, as shown in Figure 1. In the group of membranes derived from elective caesarean sections the mean amount of ANG, IGFBP-1, 
IGFBP-2, and Serpin E1 in the placental region was higher than in the cervical portion of AM. The levels of TIMP-1 in the placental region were slightly lower than in the cervical parts of these membranes. In samples from physiological deliveries higher amounts of ANG, IGFBP-1, -2 , and -3 , as well as TIMP-1, were observed in placental region, whereas the level of Serpin E1 was higher in cervical region of these membranes.

Placental portions of all amniotic membranes derived from elective caesarean sections were characterised by lower mean amount of ANG, IGFBP-2, IGFBP-3, and TIMP-1 than corresponding regions of membranes obtained after physiological deliveries. The mean levels of IGFBP-1 and Serpin E1 were similar in the placental regions of both membrane groups. Samples obtained from cervical area of membranes from elective caesarean section contained less ANG than corresponding samples of membranes from physiological delivery, whereas the respective mean levels of IGFBP-1, -2, -3, Serpin E1, and TIMP-1 in cervical regions were similar in both groups.

\section{Discussion}

The results of this screening study have shown that the amniotic membranes obtained from physiological delivery contained larger amounts of selected pro-angiogenic and growth factors, i.e. ANG and IGFBPs, than amniotic membranes from caesarean section. Of note, the mentioned biologically active factors were present predominantly in the placental region of amniotic membranes from both groups. All mentioned biologically active factors found in assessed samples of amniotic membrane may contribute to its beneficial actions as a dressing material. These factors may stimulate cell growth, proliferation, and migration of fibroblasts, epithelial cells, and vascular endothelial cells into the wound bed, and thus may actively promote wound healing [24].

Insulin-like growth factor-binding proteins are a family of factors, which regulate the half-life, availability and activity of Insulin-like growth factors (IGFs). It has been proven that co-administration of topical IGF-1 and IGFBP-1 or IGFBP-3 at wound sites enhanced stimulating effects of IGF-1 on re-epithelialisation and granulation tissue deposition. The IGFBPs display also some IGF-independent activities like regulation of cellular migration, proliferation, and pro-apoptotic activity. These properties of IGFBPs can be connected with interaction with TGF- $\beta 3$ receptor [25]. In our study IGFBP-1, -2 , and -3 were present in all amnion samples, and their amounts in membranes collected from natural deliveries were higher compared to those from caesarean section. In both groups, quantities of IGFBPs were higher in placental regions than in cervical portions of amniotic membrane.

ANG, a plasma protein belonging to the ribonuclease A superfamily, is considered to be one of the most potent
Table 1. The comparison of biologically active factors profiles of caesarean section and physiological deliveryderived amniotic membrane samples. The concentration of ANG, TIMP-1, Serpin E1, and IGFBP1-3 in amniotic membrane extracts is expressed in units of optical density

\begin{tabular}{lcc}
\hline & $\begin{array}{c}\text { Caesarean section } \\
\text { Mean } \pm \text { SD/median } \\
\text { (Min.-max.) }\end{array}$ & $\begin{array}{c}\text { Physiological delivery } \\
\text { Mean } \pm \text { SD/median } \\
\text { (Min.-max. })\end{array}$ \\
\hline ANG & $1.20 \pm 1.0 / 0.96$ & $2.24 \pm 1.42 / 2.07$ \\
& $(0-2.56)$ & $(0.62-4.61)$ \\
\hline IGFBP-1 & $1.41 \pm 0.52 / 1.3$ & $1.41 \pm 0.38 / 1.39$ \\
& $(0.82-2.37)$ & $(0.99-2.20)$ \\
\hline IGFBP-2 & $0.62 \pm 0.38 / 1.02$ & $1.17 \pm 0.92 / 1.02$ \\
& $(0.3-1.2)$ & $(0-2.85)$ \\
\hline IGFBP-3 & $0.6 \pm 0.39 / 0.66$ & $1.19 \pm 0.79 / 1.1$ \\
& $(0-0.97)$ & $(0.27-2.58)$ \\
\hline Serpin E1 & $1.13 \pm 0.58 / 0.91$ & $1.12 \pm 0.63 / 0.87$ \\
& $(0.59-2.09)$ & $(0.5-2.45)$ \\
\hline TIMP-1 & $1.84 \pm 1.01 / 1.39$ & $2.14 \pm 0.69 / 2.17$ \\
& $(1.13-3.72)$ & $(1.2-3.11)$ \\
\hline
\end{tabular}

inducers of angiogenesis in vivo. By binding to smooth muscle and endothelial cells, it activates the production of several proteases and plasmin that degrade the basement membrane components. This allows the endothelial cells to penetrate and migrate into the perivascular tissue [26]. In our study, similarly to IGFBPs, ANG in the placental region was higher than in the cervical portion of amniotic membranes, especially in samples from natural delivery.

The family of TIMPs consists of four protease inhibitors, with different affinity to various MMPs, e.g. TIMP-1 preferably binds to Membrane Type-MMPs, whereas other TIMPs are less selective. TIMPs are secreted by different types of cells, like macrophages, vascular smooth muscle cells, and platelets. They suppress the MMP activity by binding to their catalytic domain and blocking enzymatic activity [27]. Since excessive expression and hyperactivation of MMPs, particularly MMP-2 and MMP-9, has been proven to be one of pathomechanisms of delayed wound healing, the presence of MMP inhibitors in a wound environment is important for effective wound treatment [28, 29]. In our study the presence of TIMP-1 was confirmed in all assessed amniotic membrane samples. The median amount of TIMP-1 was higher in the physiological delivery group than in the caesarean section group (2.17 vs. 1.39, respectively). Comparable median amounts of TIMP-1 between cervical and placental area of the membrane were obtained in both physiological delivery and caesarean section groups.

Serpin E1, also known as a type-1 plasminogen activator inhibitor (PAI-1), primarily produced by endothelial cells, is a member of the serine protease inhibitor gene family. It acts as a main inhibitor of two serine proteases, tissue plasminogen activator (tPA) and urokinase (uPA), 

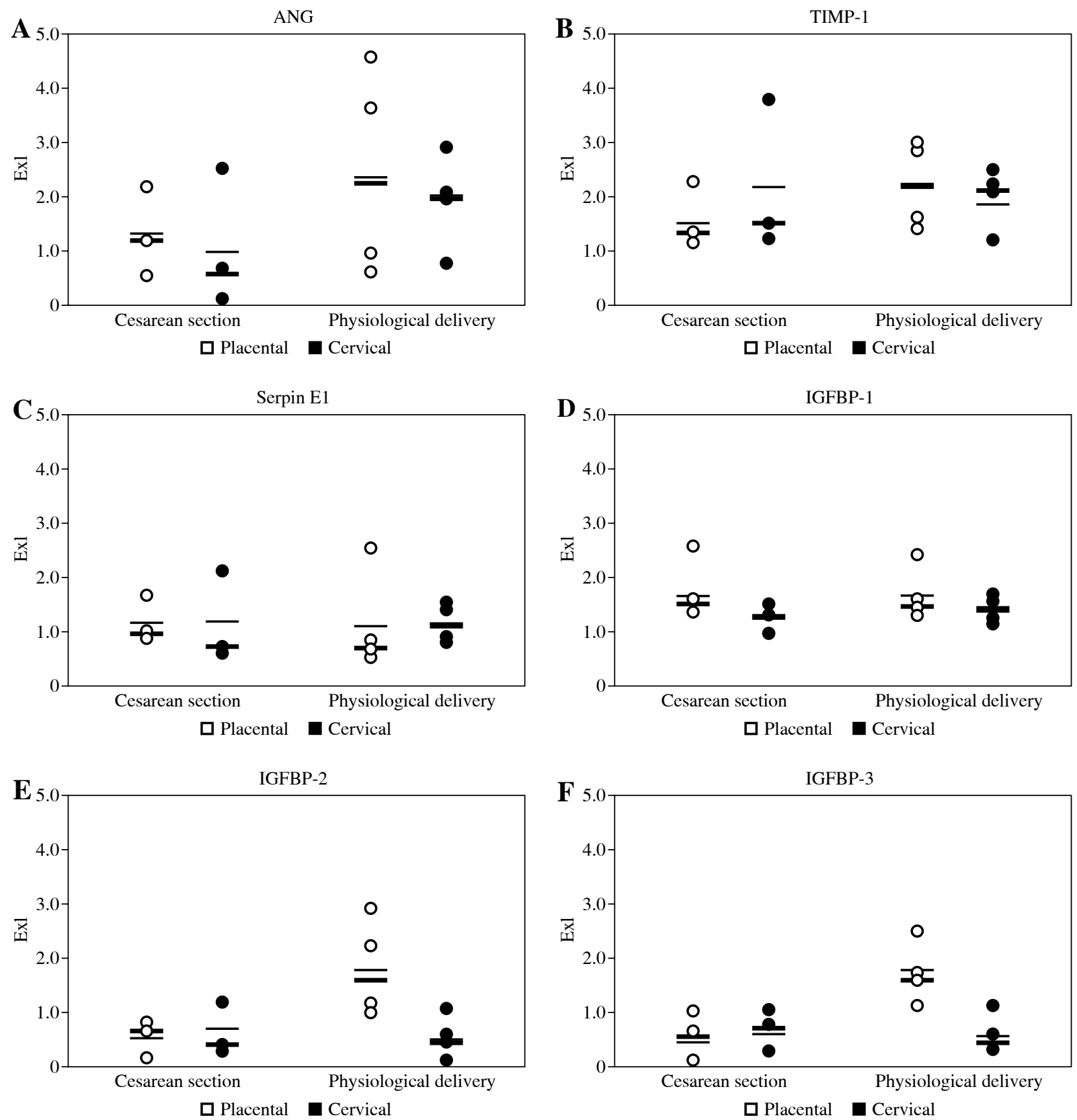

Fig. 1. The concentration of ANG, TIMP-1, Serpin E1, and IGFBP1-3 in amniotic membrane extracts expressed in units of optical density (Exl). Each dot represents the result of respective measurement in one individual amnion sample, white dots represent placental portions of each membrane, whereas black dots represent cervical portions of each membrane. Mean values of ANG, TIMP-1, Serpin E1, and IGFBP1-3 concentration in each group are indicated as dashed lines, the median values are shown as solid lines

inhibiting fibrinolysis [30]. It has been proven that serpin E1 facilitates migration of in vitro cultured cells [31]. In vivo studies on animal models have demonstrated that the expression of serpin E1 increased rapidly at the site of injury and remained elevated up to the formation of keratinocytes monolayer on the damaged skin surface [32].
A sustained high level of serpin E1 is essential to support the long-term cell motility in a wound bed, possibly by inhibition of plasmin generation [33, 34]. Research focusing on the mechanism of cancer metastasis has proven that serpin E1 exhibits an inhibitory activity against MMPs [35]. Therefore, the presence of serpin E1 in a wound bed may 
reveal beneficial effects on the wound healing process. The analysis using protein microarray has shown the presence of comparable amounts of serpin E1 in amnion samples derived from physiological deliveries and caesarean sections. The median level of serpin E1 was also similar in both placental and cervical parts of membranes in both groups.

The present study is a preliminary screening analysis and was thus performed on a limited number of samples. Based on the obtained results, it would now be possible to assess the identified biologically active factors in a larger group of AM, especially using quantitative methods such as ELISA assessment. Nevertheless, our proof-of-concept study has shown that the content of biologically active factors in AM samples is highly variable, mainly due to inter-donor variations. Moreover, it depends on the specific area of the amniotic membrane and the mode of childbirth. Despite the small number of AM samples included in the study, the results of our proof-of-concept study may explain inconsistent results of clinical research.

The presence of several biologically active factors, which regulate tissue regeneration, makes the amniotic membrane a valuable candidate for a biological dressing that actively stimulates the process of wound healing. Previous studies have shown that the content of these factors in AM samples and, thus, their biological properties may depend on various methods of AM processing and sterilisation [11, 12]. However, results of our proof-of-concept study suggest that properties of AM-derived dressing samples also depend on the part of the harvested AM sample, as well as on the delivery method. This concept was already postulated by Banerjee et al., who observed higher mitochondrial respiratory activity of AM samples derived from the placental region, in comparison to the reflected (distant from placenta) region of the membrane [36]. Our observation suggests that the placental region of $\mathrm{AM}$, especially in membranes from physiological delivery, is characterised by high concentrations of growth factors and regulators of ECM turnover, which stimulate the process of tissue regeneration. Therefore, it may be more suitable for application in a treatment of non-healing wounds. On the other hand, amniotic membranes obtained from elective caesarean section, especially their cervical portions, are relatively poor in pro-angiogenic factors. These characteristics could be potentially beneficial, e.g. for ophthalmological applications, like closure of corneal lesions and ocular surface reconstruction, where stimulation of fibroblasts proliferation or angiogenesis is not desired. However, to verify our observations, further research with larger groups is necessary.

The authors declare no conflict of interests.

\section{References}

1. Koob TJ, Lim JJ, Massee M, et al. (2004): Angiogenic properties of dehydrated human amnion/chorion allografts: ther- apeutic potential for soft tissue repair and regeneration. Vascular Cell 1: 6-10.

2. Niknejad H, Peirovi H, Jorjani M, et al. (2008): Properties of the amniotic membrane for potential use in tissue engineering. Eur Cell Mater 29: 88-99.

3. Riau A, Beuerman RW, Lim LS, et al. (2010): Preservation, sterilization and de-epithelialization of human amniotic membrane for use in ocular surface reconstruction. Biomaterials 31: 216-225.

4. Fatima A, Sangwan VS, Iftekhar G, et al. (2006): Technique of cultivating limbal derived corneal epithelium on human amniotic membrane for clinical transplantation. J Postgrad Med 52: 257-261.

5. Yang L, Shirakata Y, Shudou M, et al. (2006): New skinequivalent model from de-epithelialized amnion membrane. Cell Tissue Res 326: 69-77.

6. Muralidharan S, Gu J, Laub GW, et al. (1991): A new biological membrane for pericardial closure. J Biomed Mater Res 25: 1201-1209.

7. Zmijewski M, Pietraszek A (2005): The application of deep-frozen and radiation-sterilized human amnion as a biological dressing to prevent prolonged air leakage in thoracic surgery. Ann Transplant 10: 17-20.

8. Tauzin H, Humbert P, Viennet C, et al. (2011): Human amniotic membrane in the management of chronic venous leg ulcers. Ann Dermatol Venereol 138: 572-579.

9. Litwiniuk M, Bikowska B, Niderla-Bielinska J, et al. (2012): Potential role of metalloproteinase inhibitors from radiation sterilized amnion dressings in the healing of venous leg ulcers. Mol Med Rep 6: 723-728.

10. Mermet I, Pottier N, Sainthillier JM, et al. (2007): Use of amniotic membrane transplantation in the treatment of venous leg ulcers. Wound Repair Regen 15: 459-464.

11. Russo A, Bonci P, Bonci P (2012): The effects of different preservation processes on the total protein and growth factor content in a new biological product developed from human amniotic membrane. Cell Tissue Bank 13: 353-361.

12. Wolbank S, Hildner F, Redl H, et al. (2009): Impact of human amniotic membrane preparation on release of angiogenic factors. J Tissue Eng Regen Med 3: 651-654.

13. Litwiniuk M, Bikowska B, Niderla-Bielińska J, et al. (2011): High molecular weight hyaluronan and stroma-embedded factors of radiation-sterilized amniotic membrane stimulate proliferation of $\mathrm{HaCaT}$ cell line in vitro. Centr Eur J Immunol 36: 205-211.

14. McParland PC, Taylor DJ, Bell SC (2003): Mapping of zones of altered morphology and chorionic connective tissue cellular phenotype in human fetal membranes (amniochorion and decidua) overlaying the lower uterine pole and cervix before labor at term. Am J Obstet Gynecol 189: 1481-1488.

15. McLaren J, Malak TM, Bell SC (1999): Structural characteristics of term human fetal membranes prior to labour: identification of an area of altered morphology overlying the cervix. Hum Reprod 14: 237-241.

16. Malak TM, Bell SC (1994): Structural characteristics of term human fetal membranes (amniochorion and decidua): a novel zone of extreme morphological alteration within the rupture site. Br J Obstet Gynecol 101: 375-386.

17. El Khwad M, Stetzer B, Moore RM, et al. (2005): Term human fetal membranes have a weak zone overlying the lower uterine pole and cervix before the onset of labor. Biol Reprod 72: 720-726. 
18. El Khwad M, Pandey V, Stetzer B, et al. (2006): Fetal membranes from term vaginal deliveries have a zone of weakness exhibiting characteristics of apoptosis and remodelling. J Soc Gynecol Investig 13: 191-195.

19. Gicquel JJ, Dua HS, Brodie A, et al. (2009): Epidermal Growth Factor Variations in Amniotic Membrane Used for Ex Vivo Tissue Constructs. Tissue Eng 15: 1919-1927.

20. Hopkinson A, McIntosh RS, Tighe PJ, et al. (2006): Amniotic membrane for ocular surface reconstruction: donor variations and the effect of handling on TGF-beta content. Invest Ophthalmol Vis Sci 47: 4316-4322.

21. Moore RM, Mansour JM, Redline RW, et al. (2006): The Physiology of Fetal Membrane Rupture: Insight Gained from the Determination of Physical Properties. Placenta 27: 1037-1051.

22. Skinner SJ, Campos GA, Liggins GC (1981): Collagen content of human amniotic membranes: effect of gestation length and premature rupture. Obstet Gynecol 57: 487-489.

23. Velez DR, Fortunato SJ, Morgan N, et al. (2008): Patterns of cytokine profiles differ with pregnancy outcome and ethnicity. Hum Reprod 23: 1902-1909.

24. Barrientos S, Stojadinovic O, Golinko, et al. (2008): Growth factors and cytokines in wound healing. Wound Repair Regen 16: $585-601$

25. Edmondson SR, Thumiger SP, Werther GA, et al. (2003): Epidermal homeostasis: the role of the growth hormone and insulin-like growth factor systems. Endocr Rev 24: 737-764.

26. Distler O, Neidhart M, Gay RE, et al. (2002): The molecular control of angiogenesis. Int Rev Immunol 21: 33-49.

27. Grzela T, Bikowska B and Litwiniuk M (2011): Matrix metalloproteinases in aortic aneurysm - executors or executioners? In: Etiology, Pathogenesis and Pathophysiology of Aortic Aneurysms and Aneurysm Rupture. Grundmann R (ed.). Intech Publ: 25-54. Available from: http://www.intechopen. com/ articles/show/title/matrix-metalloproteinases-in-aorticaneurysm-executors-or -executioners-

28. Rayment EA, Upton Z, Shooter GK (2008): Increased matrix metalloproteinase-9 (MMP-9) activity observed in chronic wound fluid is related to the clinical severity of the ulcer. $\mathrm{Br}$ J Dermatol 158: 951-961.

29. Saito S, Trovato MJ, You R, et al. (2001): Role of matrix metalloproteinases 1,2, and 9 and tissue inhibitor of matrix metalloproteinase-1 in chronic venous insufficiency. J Vasc Surg 34: 930-938.

30. Ghosh AK, Vaughan DE (2012): PAI-1 in Tissue Fibrosis. J Cell Physiol 227: 493-507.

31. Ghersi G, Dong H, Goldstein LA, et al. (2002): Regulation of fibroblast migration on collagenous matrix by a cell surface peptidase complex. J Biol Chem 277: 29231-29241.

32. Providence KM, Higgins PJ (2004): PAI-1 expression is required for epithelial cell migration in two distinct phases of in vitro wound repair. J Cell Physiol 200: 297-308.

33. Providence KM, Higgins SP, Mullen A, et al. (2008): SERPINE1 (PAI-1) is deposited into keratinocyte migration "trails" and required for optimal monolayer wound repair. Arch Dermatol Res 300: 303-310.

34. Simone TM, Longmate WM, Law BK, et al. (2015): Targeted Inhibition of PAI-1 Activity Impairs Epithelial Migration and Wound Closure Following Cutaneous Injury. Adv Wound Care 4: 321-328.

35. Duffy M (2004): The urokinase plasminogen activator system: role in malignancy. Curr Pharm Des 10: 39-49.
36. Banerjee A, Weidinger A, Hofer M, et al. (2015): Different metabolic activity in placental and reflected regions of the human amniotic membrane. Placenta 36: 1329-1332. 